Organizadoras deste número

Colaboradores deste número

\section{KONSTANZE JUNGBLUTH}

Professora de linguística contrastiva e pragmática da EuropaUniversität Viadrina (Frankfurt Oder, Alemanha). Como especialista em Pragmática da línguas românicas tem estudado a relação entre formas linguísticas e modalidades textuais, escritas e orais, especialmente o uso de pronomes demonstrativos e dêixis.

\section{MÔNICA SAVEDRA}

Doutora em Linguística pela UFRJ. Realizou estágio de pósdoutorado na Universidade Duisburg-Essen (2004). Professora da Universidade Federal Fluminense, Pesquisadora do CNPq e Coordenadora do Programa de Pós-graduação em Estudos de Linguagem da UFF. Assessora científica da FAPERJ para a área de Humanidades. Desenvolve pesquisas e orienta na área de sociolinguística e línguas e culturas em contato.

\section{ADRIANA DALLA VECCHIA}

Doutoranda em Letras na Universidade Estadual de Maringá (UEM). Tem experiência na área de Letras, com ênfase em Línguística Aplicada e Língua Portuguesa.

\section{ALEXANDRE MARCELO BUENO}

Doutor pelo Programa de Pós-Graduação em Semiótica e Linguística Geral pela FFLCH-USP, fez estágio de pós-doutorado na Pontifícia Universidade Católica de São Paulo. Realizou estágio de doutoradosanduíche na Université Paris 8. Foi professor visitante da Universidade Nacional de Timor-Leste. É professor do Programa de Mestrado em Linguística da UNIFRAN.

\section{ANA LÚCIA DE MEDEIROS}

Doutora em Administração de Empresas pela Universidade Presbiteriana Mackenzie (2013). Diretora do Campus Universitário de Palmas da UFT, onde é professora do curso de ciências econômicas, do mestrado profissional em gestão de políticas públicas e do mestrado profissional em Administração Pública.

\section{ANDREW NEVINS}

Professor na Universidade Federal do Rio de Janeiro e na University College London. Sua pesquisa se concentra nas ciências da 
linguagem e novas metodologias na coleta de dados, bem como na linguística das línguas minoritárias e sua contribuição para a teoria linguística.

\section{BRUNO DEUSDARÁ}

Doutor em Psicologia Social. Professor de Linguística do Instituto de Letras da UERJ e de Língua Portuguesa e Literatura Brasileira do Instituto de Aplicação Fernando Rodrigues da Silveira (CAp-UERJ). Áreas e temáticas de interesse são a análise do discurso, estudos enunciativos, pesquisa-intervenção, interface linguagem e trabalho, produção de subjetividade e ensino de língua materna.

\section{CAROLINE SCHNEIDERS}

Doutora em Letras - Estudos Linguísticos - pela Universidade Federal da Fronteira Sul, onde é professora de Língua Portuguesa e Linguística. Realizou Pós-doutorado (Bolsista DOCFIX-FAPERGS) junto ao Laboratório Corpus/Programa de Pós-graduação em Letras da UFSM. Atua em temas vinculados à História das Ideias Linguísticas e à Análise de Discurso.

\section{DAGNA ZINKHAHN RHOBODES}

Professora de Pragmática e Linguística Contrastiva na EuropaUniversität Viadrina (Frankfurt Oder, Alemanha). Doutora em Filosofia, foi bolsista PhD da Fundação de Estudos do Povo Alemão e assistente de pesquisa com projeto de doutorado na área de usos da linguagem e comparação.

\section{DANIEL PADILHA PACHECO DA COSTA}

Doutor pelo Departamento de Letras Modernas da USP, com um estágio doutoral de um ano na Université Paris-Sorbonne (Paris IV). Professor do Curso de Tradução e do Programa de Pós-graduação em Estudos Literários do Instituto de Letras e Linguística da Universidade Federal de Uberlândia (UFU). Integrante de grupos de pesquisa sobre tradução e antiguidade clássica.

\section{DÉCIO ROCHA}

Doutor em Linguística Aplicada pela PUC-São Paulo. Professor do Instituto de Letras e do Instituto de Aplicação da UERJ. Membro do GT da Anpoll Linguagem, Enunciação e Trabalho e dos grupos de pesquisa Atelier Linguagem e Trabalho e PraLinS. Realiza pesquisas nas áreas de linguagem e trabalho e discursos didáticos, sustentando uma abordagem discursiva das práticas linguageiras. É bolsista de produtividade em pesquisa do CNPq. 


\section{DJANE ANTONUCCI CORREA}

Doutora em Letras pela UNESP. Fez pós-doutorado na Universidade Estadual de Ponta Grossa, onde é professora. Coordena o "Laboratório de estudos do texto", um programa de extensão que visa a integrar atividades de natureza extensionista às de ensino e de pesquisa. Dedica-se aos estudos críticos da linguagem escrita em âmbito transdisciplinar.

\section{ELIZANA SCHAFFEL BREMENKAMP}

Mestre em Linguística pela Universidade Federal do Espírito Santo. Especialista em contato linguístico, especialmente entre línguas de imigração, principalmente pomerânia e flamengo-zelandês, e português. Estuda os processos de manutenção e substituição das línguas minoritárias e o desenvolvimento do bilinguismo. Desenvolve um trabalho de contato linguístico sobre a imigração holandesa para Espírito Santo.

\section{EMNY NICOLE BATISTA DE SOUSA}

Doutoranda em Linguística pelo Programa de Pós-Graduação em Linguística da UFPB. Tem experiência com o ensino de português e inglês como línguas estrangeiras, no contexto da universidade, por meio do Programa de Extensão e do Programa Linguístico-Cultural para Estudantes Internacionais-PLEI, em escolas de línguas e no ensino fundamental, na Paraíba, e na ONG Canal Alliance, em São Francisco, EUA.

\section{FELIPE FLORES KUPSKE}

Doutor em Linguística Aplicada pela UFRGS, com período sanduíche na University College London (Inglaterra). Professor do Departamento de Letras Germânicas da UFBA. Membro do Laboratório de Bilinguismo e Cognição (LABICO - UFRGS). Atua nos seguintes grupos de pesquisa $(\mathrm{CNPq})$ : Fonética e Fonologia Aplicadas à Língua Estrangeira (UFSC); Ensino e formação de professores (Unochapecó); e Estudos Linguísticos e Literários (Unochapecó).

\section{FRANCISCO ARIMIR CUNHA FILHO}

Doutorando em Linguística na Universidade Federal do Pará, onde é professor. Fez sanduíche na Université François Rabelais-Tours (França). Tem experiência na área de ensino-aprendizagem de línguas, atuando principalmente nos temas ensino, letramento, português escrito para surdos e PLE. 


\section{GERTJAN POSTMA}

Investigador sênior do Meertens Institute Amsterdam, um instituto de pesquisa da Academia de Ciências da Holanda. Especialista em sintaxe diacrônica, executou um projeto para construir um analisador automático do holandês médio e recentemente escreveu uma gramática comparativa do pomerânio no Brasil.

\section{GILVAN MÜLLER DE OLIVEIRA}

Doutor em Linguística na UNICAMP. Fez o pós-doutorado na Universidade Autônoma Metropolitana Iztapalapa, no México. Professor da Universidade Federal de Santa Catarina. Secretário Executivo Adjunto da MAAYA - Rede Mundial de Multilinguismo, com sede em Paris. Atua na área de Política Linguística e História das Línguas, com foco na questão da promoção e ensino da Língua Portuguesa como língua não materna.

\section{JAKELINE A. SEMECHECHEM}

Doutora em Letras pela Universidade Estadual de Maringá (UEM/ PR), com estágio de doutoramento na Universidade de Coimbra (UC/PT). Professora da Universidade Estadual do Norte do Paraná (UENP). Tutora a distância no curso de Letras Português-Inglês a distância da UEM/Maringá. Suas pesquisas estão voltadas para a etnografia da linguagem, diversidade, multilinguismo, identidades, letramento e políticas linguísticas.

\section{JOEL AUSTIN WINDLE}

Doutor em Educação em cotutela pelas Universidades de Melbourne e Bourgogne. Professor do Departamento de Letras Estrangeiras Modernas da Universidade Federal Fluminense. Tem experiência no estudo de diversidade cultural, ensino/aprendizagem de línguas, novos letramentos e sociologia da educação. Coordena o Núcleo de Estudos Críticos em Linguagens, Educação e Sociedade (NECLES).

\section{JOELMA APARECIDA BRESSANIN}

Doutora em Linguística pela UNICAMP. Professora na Universidade do Estado de Mato Grosso. Coordena o Grupo de estudos GEPELCO, vinculado ao CNPq e ao projeto de pesquisa Políticas Públicas e Práticas de Linguagem no Centro-Oeste. Realiza pesquisas na área História das Ideias Linguísticas e Análise de Discurso, com os temas políticas de ensino e políticas de línguas, formação de professores e práticas de leitura e escrita. 


\section{JOSÉ CARLOS CHAVES DA CUNHA}

Doutor e pós-doutor em Ciências da Linguagem pela Universitá de Toulouse II (Le Mirail). Professor da Universidade Federal do Pará. Atua, principalmente, no campo do ensino-aprendizagem de línguas (materna e estrangeira). Em 2007 recebeu o título de Doutor Honoris Causa, outorgado pela Université des Antilles et de la Guyane da França.

\section{JULIA IZABELLE DA SILVA}

Doutoranda da Universidade Federal de Santa Catarina, bolsista CNPq. Tem experiência em pesquisa na área de Linguística, com ênfase nas subáreas de Sociolinguística, Línguas em contato e Análise e Descrição de línguas indígenas do ramo Jê, tronco MacroJê. Atuou como professora substituta de Língua Portuguesa no Centro de Ensino e Pesquisa Aplicada à Educação, da UFG.

\section{KAREN PUPP SPINASSÉ}

Doutora pela Technische Universität Berlin. Professora na UFRGS. Coordena os cursos de alemão do Núcleo de Ensino de Línguas em Extensão da UFRGS e os cursos da UFRGS no âmbito do Programa Idiomas sem Fronteira - Alemão, do MEC. Trabalha, principalmente, com aquisição bilíngue da linguagem, didática de ensino de línguas estrangeiras e com o ensino do alemão no Brasil em contextos de imigração.

\section{KATHY RYS}

Faz pós-doutorado no Meertens Institute Amsterdam e é pesquisadora sênior na Universidade de Antuérpia (Bélgica). Especialista em dialectologia, mais especificamente na aquisição de variação fonológica.

\section{LETÍCIA CAO PONSO}

Doutora em Teoria e Análise Linguística pela UFF, com estágiosanduíche na Universidade Eduardo Mondlane - Moçambique (Bolsa Capes). Professora do UNICARIOCA. Autora do livro Linguagem, Valores, Cidadania: Lingua Portuguesa e Literatura (EDELBRA, 2015) e coautora do livro Docência em Lingua Portuguesa: Experiências Contemporâneas (Edições CL, 2008). Pesquisadora integrante do Grupo ALMA LINGUAE. 


\section{LOURDES SERAFIM DA SILVA}

Mestranda em Letras pela UNEMAT. Professora efetiva da educação básica do Estado de Mato Grosso. Atua principalmente nos temas: aprendizagem, ensino, produção escrita.

\section{MAGED TALAAT MOHAMED AHMED ELGEBALY}

Doutor em Estudos Comparados de Literaturas de Língua Portuguesa da USP e doutor em Tradução pela Ain Shams University. Coordenador do Departamento de Língua Portuguesa na Faculdade de Idiomas e Tradução na Universidade de Assuão (Egito). Vem atuando especialmente em atividades acadêmicas em torno do ensino de Português como Língua Adicional.

\section{MARIA ELENA PIRES SANTOS}

Doutora pela Universidade Estadual de Campinas, fez pós-doutorado na mesma instituição. Professora na Universidade Estadual do Oeste do Paraná e na Universidade Estadual do Oeste do Paraná, onde coordena o Mestrado em Sociedade, Cultura e Fronteiras. Atua nos temas ensino, bilinguismo, formação de professores, educação bilíngue e políticas linguísticas.

\section{MARIA HELENA DE PAULA}

Doutora em Linguística e Língua Portuguesa pela UNESP. Professora da Universidade Federal de Goiás. Líder da Rede Goiana de Pesquisa e Estudos em "Linguagem, Memória e Cultura" da FAPEG e membro de banco de consultores ad hoc da FAPEG. Editora da Revista "Linguagem - estudos e pesquisas". Coordenadora de Pesquisa e Pós-graduação da UFG/Regional Catalão.

\section{MARIA LIDIANI KÄFER}

Mestre em Letras pela UFRGS, na área de Linguística Aplicada. Participou como pesquisadora voluntária do Projeto binacional ALMA-H (Atlas Linguístico-Contatual das Minorias Alemãs na Bacia do Prata: Hunsrückisch). Foi integrante do Grupo de Estudos da Escrita do Hunsrückisch e atuou como professora de língua alemã no Núcleo de Ensino de Línguas em Extensão da UFRGS.

\section{NEIVA MARIA JUNG}

Doutora em Letras pela UFRGS. Professora da Universidade Estadual de Maringá (UEM). Coordena o grupo de pesquisa Letramento, Etnografia, Interação, Aprendizagem e Multilinguismo (LEIAM). 
Tem experiência na área de Linguística Aplicada, pesquisando sobre os seguintes temas: letramento, identidades sociais, multilinguismo, etnografia e fala-em-interação social.

\section{PETER KLAUS ROSENBERG}

Professor de Linguística da Faculdade de Artes e Humanidades da Europa- Universität Viadrina (Frankfurt Oder, Alemanha). Atua na área de usos da linguagem e comparação. Tem interesse nas áreas da sociolinguística, dialectologia, minorias etnolinguísticas, língua e cultura e contato linguístico, entre outras.

\section{PHELLIPE MARCEL DA SILVA ESTEVES}

Mestre em Letras e doutor em Estudos de Linguagem. Professor do Departamento de Estudos da Linguagem da UERJ. Tem experiência na área de Linguística, Comunicação e Produção Editorial, e pesquisa principalmente os seguintes temas: análise do discurso, editoração, história do livro, história das ideias linguísticas e ensino de línguas.

\section{POLIANA COELI COSTA ARANTES}

Doutora em Linguística pela Universidade Federal de Minas Gerais, com período de doutorado sanduíche (bolsa CAPES/DAAD) na Albert-Ludwigs-Universität Freiburg (Alemanha). Professora de Língua e Literatura Alemã da UERJ. Membro do Forschungsgruppe Medienkultur do FRIAS (Freiburg Institut of Advanced Studies).

\section{RUBENS MARQUES DE LUCENA}

Doutor em Linguística pela Universidade Federal da Paraíba, com área de concentração em Teoria e Análise Linguística. Professor na mesma instituição, onde atua no Departamento de Letras Estrangeiras Modernas e no Programa de Pós-Graduação em Linguística (PROLING). Suas áreas de interesse em pesquisa são Sociolinguística e Fonologia.

\section{SOCORRO CLÁUDIA TAVARES DE SOUSA}

Doutora em Linguística pela Universidade Federal do Ceará. Professora do Departamento de Letras Clássicas e Vernáculas e do Programa de Pós-Graduação em Linguística (Proling) da UFPB. É líder do Núcleo de Estudos em Política e Educação Linguística (NEPEL). 


\section{TAÍS REGINA GÜTHS}

Mestre em Linguagem, Identidade eSubjetividade pela Universidade Estadual de Ponta Grossa. Professora de língua portuguesa da rede estadual de ensino do Paraná e professora colaboradora no curso de Letras da Universidade Estadual de Ponta Grossa.

\section{THOMAS KREFELD}

Doutor pela Albert-Ludwigs-Universität in Freiburg/Br. Livredocente pela Johannes-Gutenberg-Universität de Mainz. Professor de Filologia Românica (Linguística) na Ludwig-MaximiliansUniversität, em Munique. Desde 2013 é CEO do Instituto da Cultura Alemã e da História da Europa do Sudeste (IKGS). Tem interesse nas áreas: variedades diacrônicas e sincrônicas, formação do romance em línguas nacionais e integração metodológica e prática das novas mídias para a investigação linguística.

\section{VANESSA MASSONI DA ROCHA}

Professora de língua francesa e literaturas francófonas na Universidade Federal Fluminense. Doutora em Estudos de Literatura e Mestre em Literaturas Francófonas pela Universidade Federal Fluminense. Faz estágio de pós-doutorado na Universidade do Estado do Rio de Janeiro. Desenvolve pesquisas sobre a memória (pós)colonial nas Antilhas francesas a partir, sobretudo, de narrativas de Simone Schwarz-Bart et de Raphaël Confiant.

\section{WAGNER RODRIGUES SILVA}

Fez pós-doutorado em Linguística Aplicada pela The Hong Kong Polytechnic University (PolyU) e pela Aswan University (Egito). Professor da Universidade Federal do Tocantins - UFT e bolsista de produtividade do $\mathrm{CNPq}$ (PQ-2). Tem experiência na área de Linguística Aplicada, atuando principalmente nos Estudos do Letramento.

\section{ZACARIAS ALBERTO SOZINHO QUIRAQUE}

Mestrando em Estudos da Linguagem na Universidade Federal de Goiás/Regional Catalão. Professor na Universidade Eduardo Mondlane (Moçambique). Bolsista CNPq. Membro do Grupo de Estudos e Pesquisas em História do Português (GEPHPOR), no Programa de Pós-Graduação Mestrado em Estudos da Linguagem (PMEL) da UFG/RC. Atua nos estudos da morfologia lexical das línguas bantu e da língua portuguesa. 